\title{
Metagenomic Analysis of Oral Microbiome during pregnancy
}

Huda Farah, Muram Elamin, Rahaf Nader, Rana AL Absi, Salma Bouabidi, Sara Suleiman, Shahd Nasr, Shouq Al-Rumaihi, Zain Zakaria, Maha Al-Asmakh

\section{Department of Biomedical Science, College of Health Sciences}

\section{INTRODUCTION}

Pregnancy is associated with several hormonal, immunological and metabolic changes that are necessary to support the growing fetus. The pathological and physiological changes in pregnancy are greatly affected by the maternal microbiota [1]. During pregnancy, the composition of the maternal microbiota can change dramatically with fluctuations in certain bacteria's richness. The maternal oral cavity and gut incorporate diverse microbiota that play significant roles in preventing diseases, protecting the health of the oral cavity and maintaining oral hemostasis [2]. However, the specific roles that the oral microbiome plays during pregnancy are yet to be fully discovered [3].

\section{OBJECTIVES}

The role of oral microbiota during pregnancy is not well understood and has not been intensely studied. This study aim to analyze changes in the salivary microbiome in healthy pregnant women enrolled in the Qatari Birth Cohort (QbiC) and delineate oral microbiome markers characteristic of pregnancy.

\section{METHODOLOGY}

1. Participant's data collection from QBB.

2. Saliva samples collection and DNA extraction.

3. DNA amplification using PCR.

4. MiSeq Sequencing for sample richness and diversity analysis.
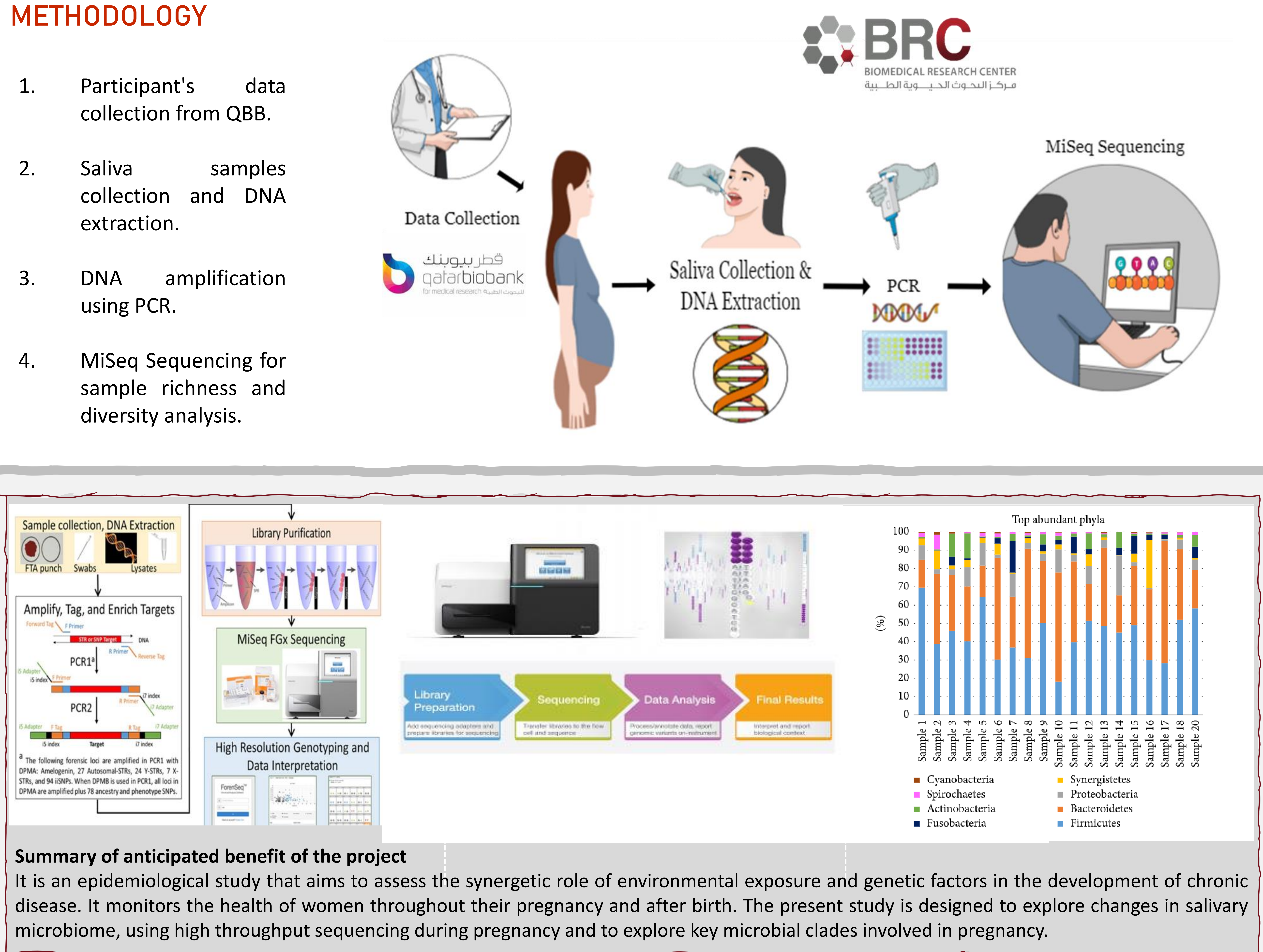

\section{REFERENCES}

1. Susic, D., Bai, M., \& Henry, A. (2020). Microbiota and pregnancy. Microb. Health. Dis., 2(3). 1-11.

2. Deo, P. N.; Deshmukh, R. (2019). Oral microbiome: Unveiling the fundamentals. Journal of oral and maxillofacial pathology : JOMFP, 23 (1), $122-128$.

3. Fujiwara, N.; Tsuruda, K.; Iwamoto, Y.; Kato, K.; Odaki, T.; Yamane, N.; Hori, Y.; Harashima, Y.; Sakoda, A.; Tagaya, A.; Komatsuzawa, H.; Sugai, M.; Noguchi, M. (2017)

Significant increase of oral bacteria in the early pregnancy period in Japanese women. Journal of investigative and clinical dentistry, 8 (1). 